Международная Объединенная Академия Наук Межрегиональный Гуманитарно-Технический Университет

\title{
Научные тенденции: Вопросы точных и технических наук
}

\author{
Сборник научных трудов \\ по материалам \\ XXIX международной научной конференции
}

12 июля 2020 г.

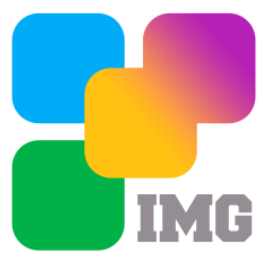

Санкт-Петербург 2020 
ББК 30

Научные тенденции: Вопросы точных и технических наук. Сборник научных трудов по материалам XXIX международной научно-практической конференции 12 июля 2020 г. Изд. ЦНК MOAH, 2020. - 24 c.

\section{SPLN 001-000001-0668-TT \\ DOI 10.18411/sciencepublic-12-07-2020 \\ IDSP sciencepublic-12-07-2020}

В сборнике научных трудов собраны материалы из различных областей научных знаний. В данном издании приведены все материалы, которые были присланы на XXIX международную научно-практическую конференцию Научные тенденции: Вопросы точных и технических наук

Сборник предназначен для научных работников, преподавателей, аспирантов и студентов.

Все материалы, размещенные в сборнике, опубликованы в авторском варианте. Редакция не вносила коррективы в научные статьи. Ответственность за информацию, размещенную в материалах на всеобщее обозрение, несут их авторы.

Информация об опубликованных статьях будет передана в систему ELIBRARY и наукометрическую базу SPINDEX

Электронная версия сборника доступна на сайте ЦНК MOAН. Сайт центра: conf.sciencepublic.ru 


\section{Cоgержанше}

РАЗДЕЛ І. ИНФОРМАЦИОННЫЕ ТЕХНОЛОГИИ 4

Донец С.А. Имитационная система 3D визуализации переноса радиационного загрязнения ....

Доржиев А.С. Обучение с подкреплением для беспилотных летательных аппаратов .... 5

Моисеев И.Ю. Тестирование метода совместного использования параметров в мультиагентном глубоком обучении с подкреплением

РАЗДЕЛ ІІ. АРХИТЕКТУРА

Алексеев С.И. Проектирование свайных фундаментов с оптимизацией выбираемой осадки

РАЗДЕЛ ІІІ. ФИЗИКА

Сафаров ШІ.Р., Ойматова Х.Х., Рафиев С.С., Сафаров М.М., Файзова М.А. Расчет одного из основных термодинамических потенциалов (энергия Гельмгольца) тернарных систем.

Новиков Н.И., Новиков В.Н. К вопросу устойчивости функционирования групповых производственных систем.... 


\title{
РАЗДЕЛ І. ИНФОРМАЦИОННЫЕ ТЕХНОЛОГИИ
}

\author{
Донец С.А. \\ Имитационная система 3D визуализации переноса радиационного загрязнения \\ Военный учебно-научный центр Военно-воздушных сил «Военно-воздушная \\ академия имени профессора Н.Е. Жуковского и Ю.А. Гагарина»
}

(Россия, Воронеж)

doi:10.18411/sciencepublic-12-07-2020-01

idsp: sciencepublic-12-07-2020-01

\section{Аннотация}

В статье рассмотрены актуальные вопросы применения имитационных систем 3D визуализации, их применения для ликвидации чрезвычайных ситуаций природного и техногенного характера, минимизации их последствий. Определена целесообразность использования имитационных систем для подготовки специалистов.

Ключевые слова: имитационные системы, 3D визуализация, чрезвычайные ситуации природного и техногенного характера.

В настоящее время, время стремительного ускорения научно-технического прогресса, бурного развития технологий и производств, связанных с атомной энергией военного и гражданского назначения, многократно возрастает риск возникновения техногенных катастроф, чрезвычайных ситуаций, которые могут иметь тяжелые последствия как регионального, так и глобального масштаба. К сожалению, примеров таких событий в современной истории, более чем достаточно. Это аварии, с катастрофическими последствиями на атомных электростанциях Чернобыльской (1986 г.), Фукусима-1 (2011 г.), гибель советской атомной подводной лодки «Комсомолец» в 1989 г. и др. Следует учитывать и природные катастрофы, многочисленные землетрясения, процессы, связанные с вулканической деятельностью.

Аварии на ядерных и радиационно-опасных объектах, как правило, носят серьезные последствия. Они связаны с распространением радиоактивных веществ и заражением радиоактивными элементами территорий. Службам и специалистам, участвующим в ликвидации последствий аварийных ситуаций, приходиться действовать в условиях быстроизменяющейся окружающей обстановки и нехватки достоверной оперативной информации. Это приводит к задержкам в принятии решений, что негативно сказывается на результатах ликвидации последствий.

Существенно сократить время реагирования на изменяющуюся ситуацию может использование компьютерных технологий, в частности имитационных систем 3D визуализации.

Среди многообразия имитационных систем можно выделить программный продукт группы компаний «НЕОЛАНТ» (Россия). Система обеспечивает наглядное отображение данных, полученных с использованием расчётных комплексов института проблем безопасного развития атомной энергетики РАН (ИБРАЭ).

Эта система способна решать следующие задачи:

- наглядное представление расчётных данных о перемещении загрязняющих примесей в приземном слое воздуха (на основе реальных характеристик выбрасываемой смеси, метеоусловий, расположения точки выброса);

- трёхмерное динамическое и масштабируемое отображение элементов производственной и городской застройки (способствует правильным и оперативным действиям персонала аварийно-спасательных 
формирований в условиях работы в зоне радиоактивного загрязнения, оптимизации комплекса защитных мероприятий);

- визуальное определение полей загрязнения (расчётных и экспериментальных) на трёхмерных моделях элементов промышленной и городской застройки;

— в динамике представление данных по переносу загрязняющих примесей в приземном слое воздуха, а также по полям загрязнения;

- представление информации, характеризующей дозы по маршрутам полей радиоактивного загрязнения и т. п.;

- подготовка данных для оптимизации работы средств робототехники;

- создание имитационных программ для отработки плана действий аварийных служб и подразделений, участвующих в ликвидации последствий чрезвычайных ситуаций [1].

В целом, имитационное 3D моделирование дает большие преимущества: сбор и хранение информации о зданиях, сооружениях различного назначения, состояния путей эвакуации. Позволяет быстро оценить ситуацию на 3D модели, обеспечить: ликвидацию аварии, минимизировать последствия, быструю и слаженную работу аварийных служб и подразделений.

Для работы с имитационной системой «НЕОЛАНТ» необходима подготовка специалистов. Система формирует у обучаемых комплексное, системное, структурное понимание динамических процессов, происходящих в зоне чрезвычайной ситуации, алгоритм действий для ликвидации аварии и минимизации ее последствий. Кроме того, актуальность имитационной системы заключается в том, что подобные, чрезвычайные ситуации невозможно произвести из-за их опасности, значительных материальных затрат на натурное моделирование.

Освоение данного программного продукта поможет обучаемым приобрести необходимые профессиональные компетенции.

К недостаткам можно отнести необходимость создания достоверной информационной модели, что требует привлечения усилий разнопрофильных специалистов [2].

1. http://www.neolant.ru/projects/news_detail.php?ID=204 (дата обращения 06.07.2020)

2. Донец С.А., Санникова С.М. Применение 3D визуализации для проведения пожарно-тактических расчетов с учетом современных информационных технологий // Пожарная безопасность: проблемы и перспективы. - 2017. Т. 1. № 1 (8). С. 58-60.

Доржиев A.C.

Обучение с подкреплением для беспилотных летательных аппаратов

Финансовый университет при Правительстве Российской Федерации (Россия, Москва)

doi:10.18411/sciencepublic-12-07-2020-02

idsp: sciencepublic-12-07-2020-02

Научный руководитель Никитин П.В.

Беспилотные летательные аппараты (БПЛА), такие как квадрокоптеры, являются активно развивающейся сферой авиастроения. Простота обслуживания и быстродействие по сравнению с пилотируемой и наземной техникой, маневренность, небольшие габариты, способность нести в полете полезные грузы, а также возможность установки камер для съемки позволили решать широкий спектр задач, начиная от 
строго военных задач патрулирования и мониторинга территорий до оперативных мобильных дефибрилляторов для оказания медицинской помощи [1].

Современный квадрокоптер - это беспилотный летательный аппарат (БПЛА) с четырьмя моторами, одна пара которых вращается по часовой стрелке, вторая - против [2]. В связи с этим пропадает необходимость в хвостовом винте, который имеется у вертолета. Управление движением осуществляется путём изменения скорости вращения винтов.

Технологии искусственного интеллекта, машинное обучение, большие данные также имеют богатую сферу применения: а именно: скоринговые, прогнозные и рекомендательные системы, распознавание объектов, поиск аномалий и т.д $[3,4]$. В ряде задач для создания подобных программных продуктов используются нейронные сети. Они позволяют реализовывать более сложные модели, которые, например, сами добывают и анализируют данные, а затем, обучаясь на них, корректируют свои дальнейшие действия. Такие модели называются самообучающимися и реализуются методами обучения с подкреплением.

Обучение с подкреплением (ОсП или RL - Reinforcement Learning) - это раздел машинного обучения, при котором агент взаимодействует с окружающей средой, тем самым получает некоторый опыт, на основе которого корректирует свои дальнейшие действия. На рис. 1 приведены схема и основные термины ОсП:

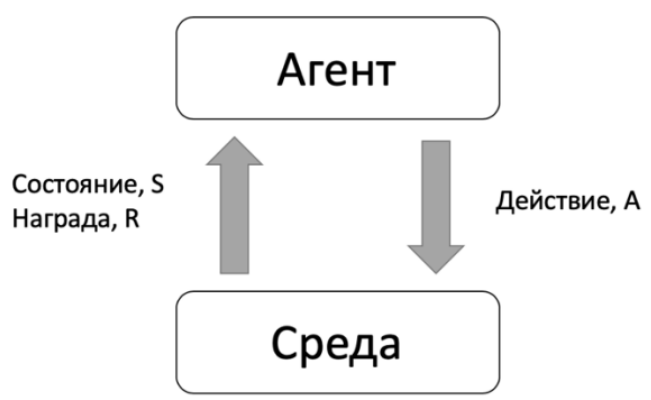

Рис. 1. Схема итерации обучения с подкреплением

Состояние - это фиксированное или динамическое положение агента. Множество различных действий агента называется «пространством действий» или действием. Среда - это место, где агент существует и с которым взаимодействует. Награда представляет собой функцию, которая служит для анализа действий агента, настройки алгоритма обучения и его оптимизации. Она зависит от текущего состояния мира и выбранного действия, а также стратегии, которая является совокупностью правил, по которым агент выбирает следующее действие.

ОсП может применяться в ряде задач коптеров, таких как: полеты по траектории, преследование цели, дроны-регулировщики и т.д.

В качестве примера рассмотрим применение ОсП для того, чтобы научить коптер взлетать. Введем агента, который управляет дроном, устанавливая случайным образом обороты в секунду на каждом из его четырех моторов. Задача взлета сводится к перемещению из начальной точки $(0,0,0)$ в целевую точку $(0,0,20)$ в координатах $(\mathrm{x}$, y, z). Агент награждается в случае, если коптер взлетел и не разбился. Штрафуется в случае крушения при попытке взлета.

Для решения данной задачи используется алгоритм Deep Deterministic Policy Gradient (DDPG), который применяется для случая, когда управляющие команды представляют собой значения из непрерывных пространств [5]. В нашей задаче возможных значений оборотов двигателя, которые выбирает агент, теоретически бесконечно много, поэтому нужно, чтобы алгоритм выдавал конкретные значения, которые нам необходимо применить в текущей ситуации. 
На входе алгоритм принимает текущее состояние агента $\mathrm{S}$, которое обладает свойством марковости, то есть включает в себя всю информацию, необходимую для предсказания следующих состояний системы. На основе состояния алгоритм выдает информацию о действии $\mathrm{A}$, которое необходимо сделать, чтобы обеспечить оптимальное поведение, которое ведет к максимизации награды. Награда R - это вещественное число, которое используется для обучения алгоритма. Награда выдается в момент, когда агент, находясь в состоянии $\mathrm{S}$, совершает действие А и переходит в состояние $\mathrm{S}^{\prime}$. Для обучения эти алгоритмы используют информацию о том, что они делали в прошлом и какой при этом был результат. Эти элементы опыта состоят из 4x компонентов (S, A, R, S') [6]. Такие четверки мы складываем в массив опыта и далее используем для обучения.

Обучение реализуется с помощью двух нейросетей: $\mu(\mathrm{S})$ - актор (действует), который возвращает нам вектор $\mathrm{A}$, компоненты которого являются значениями соответствующих управляющих сигналов. Вторая нейросеть $\mathrm{Q}(\mathrm{S}, \mathrm{A})$ - критик. Она возвращает оценку q действия А в состоянии $\mathrm{S}$. Критик используется для обучения актора и обучается с помощью уравнения Беллмана.

Q-функция актора:

L-функция:

$$
\mathrm{Q}^{\mu}\left(\mathrm{s}_{\mathrm{t}}, \mathrm{a}_{\mathrm{t}}\right)=\mathrm{E}_{\mathrm{r}_{\mathrm{t}} \mathrm{s}_{\mathrm{t}+1} \sim \mathrm{E}}\left[\mathrm{r}\left(\mathrm{s}_{\mathrm{t}}, \mathrm{a}_{\mathrm{t}}\right)+\gamma \mathrm{Q}^{\mu}\left(\mathrm{s}_{\mathrm{t}+1}, \mu\left(\mathrm{s}_{\mathrm{t}+1}\right)\right)\right]
$$

Уравнение Беллмана:

$$
L\left(\theta^{Q}\right)=E_{s_{t} \sim \rho^{\beta}, a_{t} \sim \beta, r_{t} \sim E}\left[\left(Q\left(s_{t}, a_{t} \mid \theta^{Q}\right)-y_{t}\right)^{2}\right]
$$

$$
\left.y_{t}=r\left(s_{t}, a_{t}\right)+\gamma Q\left(s_{t+1}, \mu\left(s_{t+1}\right) \mid \theta^{Q}\right)\right]
$$

Обучение критика происходит с помощью градиента от оценки критика $\nabla Q(S, \mu(S))$ по весам актора:

$$
\begin{aligned}
& \nabla_{\theta^{\mu}} \approx \approx \mathrm{E}_{\mathrm{s}_{\mathrm{t}} \sim \rho^{\beta}}\left[\left.\nabla_{\theta^{\mu}} \mathrm{Q}\left(\mathrm{s}, \mathrm{a} \mid \theta^{\mathrm{Q}}\right)\right|_{\mathrm{s}=\mathrm{s}_{\mathrm{t}}, \mathrm{a}=\mu\left(\mathrm{s}_{\mathrm{t}} \mid \theta^{\mathrm{Q}}\right)}\right] \\
& =\mathrm{E}_{\mathrm{s}_{\mathrm{t}} \sim \rho^{\beta}}\left[\left.\left.\nabla_{\mathrm{a}} \mathrm{Q}\left(\mathrm{s}, \mathrm{a} \mid \theta^{\mathrm{Q}}\right)\right|_{\mathrm{s}=\mathrm{s}_{\mathrm{t}}, \mathrm{a}=\mu\left(\mathrm{s}_{\mathrm{t}}\right)} \nabla \theta_{\mu} \mu\left(\mathrm{s} \mid \theta^{\mu}\right)\right|_{\mathrm{s}=\mathrm{s}_{\mathrm{t}}}\right]
\end{aligned}
$$

Таким образом, алгоритм состоит из 5 шагов:

1) Выбираем партию из $\mathrm{N}$ элементов опыта (S, A, R, S')

2) Рассчитываем функции $y$ и $L$

3) Обучаем критика с помощью вычисленной $L$

4) Берем градиент по весам актора $\nabla Q(S, \mu(S))$ и с помощью него корректируем веса нейронной сети актора

5) Повторяем шаги 1-4 до желаемого результата

Результат обучения и симуляции в Jupyter Notebook представлены на рис.2, где по вертикальной оси - награда, по горизонтальной оси - эпизоды обучения.

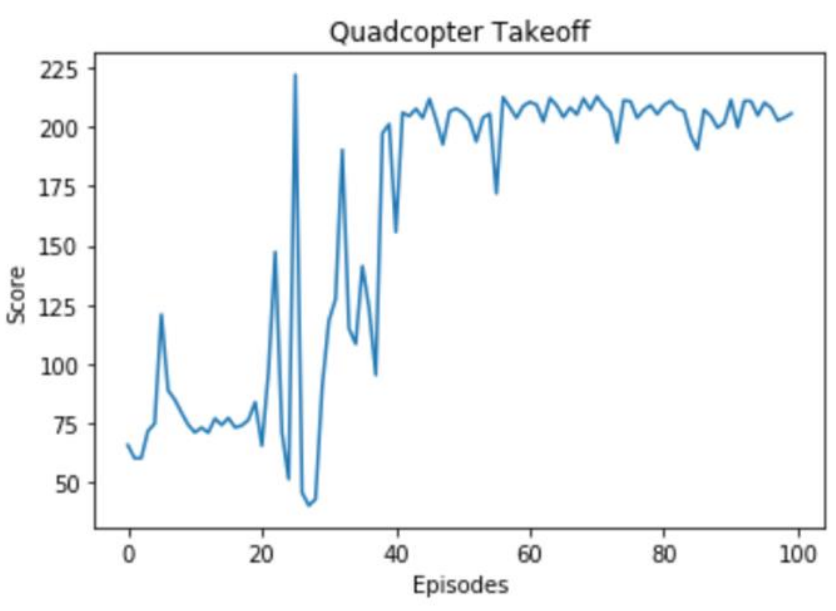

Рис. 2. График награды 
По графику награды можно заметить, что примерно после 40 попытки агент понимает, как нужно задействовать моторы коптера, чтобы взлететь, о чем свидетельствует уровень награды, который в последующие эпизоды колеблется около максимального значения.

Таким образом, в данной статье разобрано одно из применений RL для задач коптеров. Подобных задач, стоящих на стыке техники, транспорта и ОсП, много: беспилотные автомобили, шагающие роботы, интеллектуальные манипуляторы и т.д [7]. Поэтому, дальнейшие исследования в рамках этих направлений могут привести к созданию умных машин, способных обучаться, ставить и решать задачи самостоятельно. Это позволит автоматизировать промышленность, городской транспорт, а также расширит технические возможности для космических исследований.

$$
\text { *** }
$$

1. Хамзатов М. Особенности развития беспилотной авиации в современных условиях [Электронный pecypc]. - режим доступа: URL: http://uav.ru/articles/hmm.pdf (дата обращения: 07.07.2020)

2. Квадрокоптер для любительской съемки [Электронный ресурс]. - режим доступа: URL: http://infocopter.ru/kvadrokoptery-dlya-lyubitelskoj-semki-obzor-modelej/ (дата обращения: 10.06.2020)

3. Сюрмаков Р. Применение машинного обучения и Data Science в промышленности [Электронный pecypc]. - режим доступа: URL: https://vc.ru/ml/79368-primenenie-mashinnogo-obucheniya-i-datascience-v-promyshlennosti (дата обращения: 07.07.2020)

4. Никитин П.В., Баркова А.С. Математические методы для определения оценки резерва в страховании. Часть 1. Метод цепной лестницы // Вестник евразийской науки. 2019. Т. 11. № 6. С. 43.

5. Курама В., Алла С. Обучение с подкреплением на языке Python [Электронный ресурс]. - режим доступа: URL: https://habr.com/ru/company/piter/blog/434738/ (дата обращения: 26.06.2020)

6. Timothy P. Lillicrap, Jonathan J. Hunt, Alexander Pritzel, Nicolas Heess, Tom Erez, Yuval Tassa, David Silver, Daan Wierstra. Continuous control with deep reinforcement learning. URL: https://arxiv.org/abs/1509.02971 (дата обращения 25.06.2020)

7. Обучение с подкреплением / Р.С. Саттон, Э.Г. Барто; пер. с англ. - М.: БИНОМ. Лаборатория знаний, 2011. - 399 с.

\section{Моисеев И.Ю. \\ Тестирование метода совместного использования параметров в мультиагентном глубоком обучении с подкреплением ФГБОУ ВО «Финансовый университет при Правительстве Российской Федерации» \\ (Россия, Москва)}

doi:10.18411/sciencepublic-12-07-2020-03

idsp: sciencepublic-12-07-2020-03

Научный руководитель Никитин П.В.

\section{Введение}

Мультиагентное обучение с подкреплением является активно развивающейся ветвью машинного обучения, и имеет множество прикладных областей, от имитации рынка до системы управления дроном. [1-2]

Большинство моделей обучают агентов по независимым политикам. В результате каждый агент может действовать независимо от других агентов и центрального контроллера. Обучение подобных агентов сталкивается с проблемами изза нестационарности среды.

Нестационарная среда - среда, которая изменяется в процессе обучения. Нестационарность сильно усложняет обучение, ведь знания агента о среде со временем устаревают. 
В работе [3] был предложен способ обучения агентов методом совместного использования параметров. При этом методе агенты имеют часть общих параметров вплоть до того, что они могут обучаться одной политике. Это помогает агентам получить информацию друг о друге быстрее и тем самым ускорить процесс обучения. Это подтверждает теорема, доказанная в работе [3]. В данной работе рассматривается реализация обучения модели с применением независимых агентов и агентов, применяющих совместное использование параметров. Сравнивается эффективность рассмотренных методов.

\section{Реализация модели и сравнение результатов.}

Реализуем модель языке Python с использованием библиотек Ray и TensorFlow. Обучение будем проводить в игре Multiwalker.

Multiwalker представляет собой простую 2D игру, в которой агенты -3 робота, держат на своей спине блок. Задача роботов - пройти как можно большее расстояние не уронив блок. Каждый агент управляет двумя ногами, имеющими по 2 точки сцепки каждая - все пространство действий содержит в себе возможные движения ног и представляет собой 4-х элементный вектор. Пространство обозрения это 32-х элементный вектор. Роботы получают информацию с помощью симулируемого лидара. Восприятие среды у агентов ограничено, они видят лишь часть среды перед собой. Каждый агент получает небольшую награду за прохождение участка пути (1 единица за 1 условное деление пути). Штраф дается за движение в обратном направлении (по такой же цене) а также за падение блока (100 единиц). Одна игровая сессия включает в себя 500 шагов.

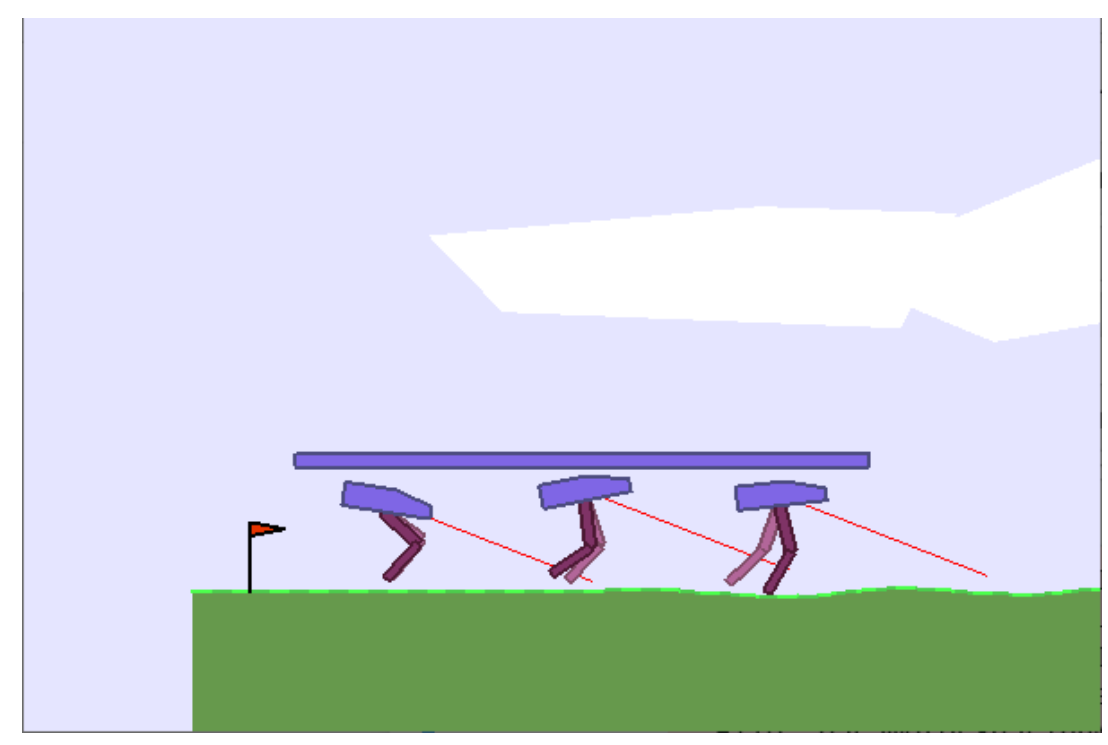

Рисунок - игра Multiwalker

В качестве метода поиска оптимальной стратегии используем Proximal Policy Optimization (PPO). [4] Данный метод относится к методам Policy Optimization - Actor critic.

В методе РРО на вход нейросети подаются наблюдения агентов. На выходе же оказываются действия агентов и оценка качества этих действий. Причем оценка является относительной - это критерий того, на сколько ситуация станет лучше после совершенного действия по сравнению с тем что есть сейчас. Эта оценка в дальнейшем используется для корректировки весов нейросети. Для недопущения резких скачков во время обучения максимальное значение модуля оценки ограничивают небольшим числом. На РРО в настоящее время обучают большинство агентов в мире обучения с подкреплением. 


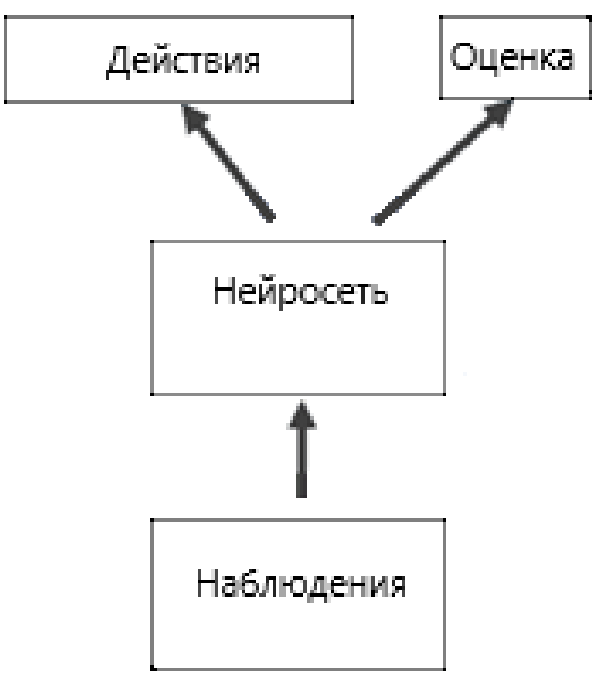

Рисунок-схема метода РРО

Нейросеть представляет собой полносвязную сеть с двумя скрытыми и одним выходным слоями. На вход подается тензор содержащий 32-х элементные векторы наблюдения агента. На первом слое находится 400 нейронов, на втором - 300. Оба слоя содержат функцию активации Relu - отсечение отрицательной части. На выходе сети слой без функции активации. Нейросеть выдает тензоры, содержащие 4-х элементные векторы.

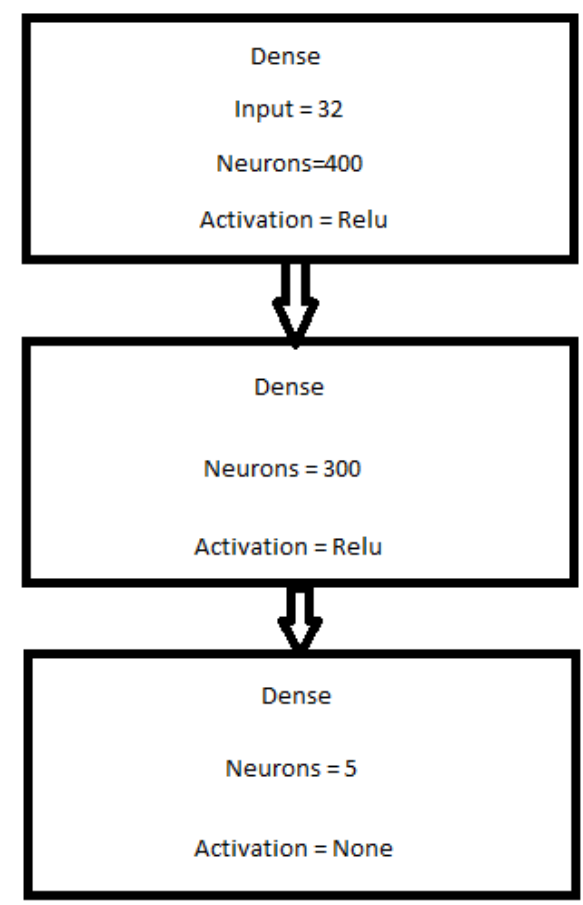

Рисунок-схема нейронной сети

При обучении использовались следующие гиперпараметры:

— Число эпох: 400;

— Размер обучающего пакета: 500;

- Размер тестового пакета: 50;

- Мини-пакеты для стохастического градиентного спуска: 100.

Результаты обучения представим в виде графика. 


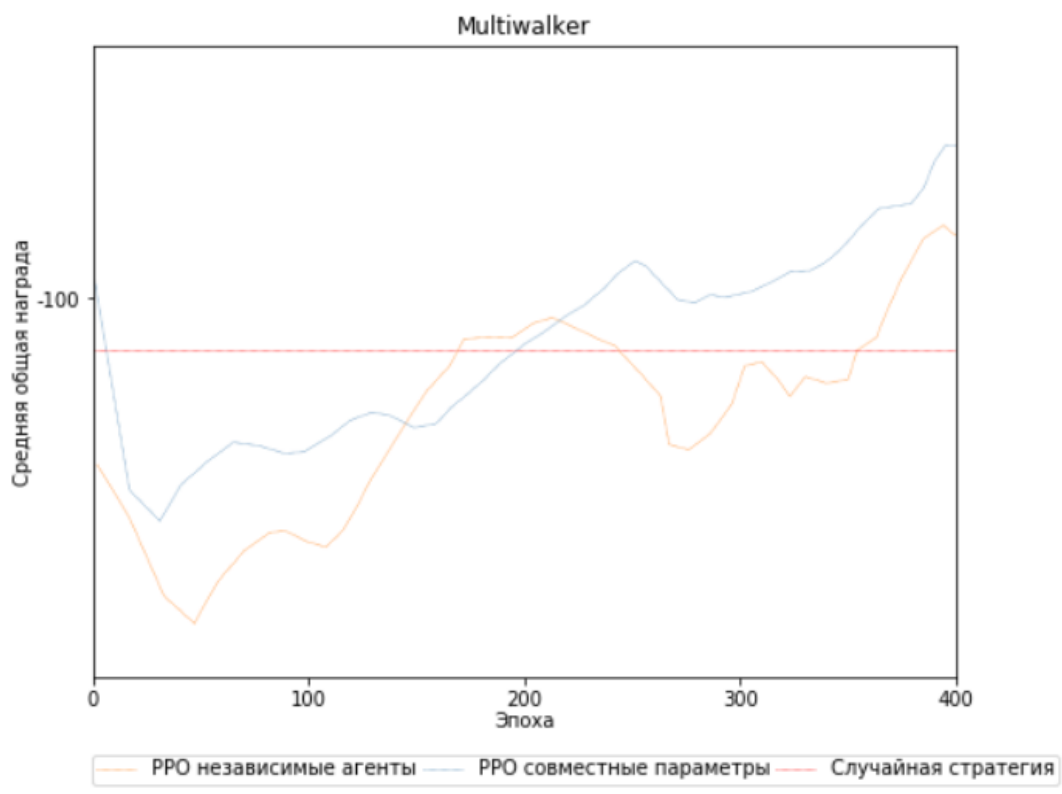

Рисунок-результаты обучения

Из графиков видно, что уже после 220 эпох метод с применением совместного использования параметров показывает лучший результат, чем метод с независимыми агентами. Для наглядности также приведен график случайной стратегии. Наибольшей награды в -93,8 единиц достигает метод РРО с совместным использованием параметров на 395 эпохе.

Вывод

В данной работе рассмотрена реализация двух моделей мультиагентного глубокого обучения с подкреплением. Представлены результаты обучения агентов. Подтверждены теоретические результаты о более быстром ходе обучения модели с совместным использованием параметром в сравнении с модели с независимыми агентами.

\section{$* * *$}

1. Gong, C., Wu, D., Gong, N., Qi, R. Multi-agent mixed complementary simulation of natural gas upstream market liberalization in China // Energy. 2020. №200,117535.

2. Hammami, S.E., Afifi, H., Moungla, H., Kamel, A. Drone-Assisted Cellular Networks: A Multi-Agent Reinforcement Learning Approach // IEEE International Conference on Communications. 2019-May. №8762079.

3. Justin K Terry, Nathaniel Grammel, Ananth Hari, Luis Santos, Benjamin Black, Dinesh Manocha Parameter Sharing is Surprisingly Useful for Multi-Agent Deep Reinforcement Learning // arXiv:2005.13625v1 [cs.LG]. 27 May 2020.

4. Proximal Policy Optimization // OpenAI Spinning Up URL: https://spinningup.openai.com/en/latest/algorithms/ppo.html (дата обращения: 10.07.2020). 


\title{
РАЗДЕЛ ІІ. АРХИТЕКТУРА
}

\author{
Алексеев С.И. \\ Проектирование свайных фундаментов с оптимизацией выбираемой осадки \\ Петербургский государственньй университет путей сообщения императора \\ Александра I \\ (Россия, Санкт-Петербург)
}

doi:10.18411/sciencepublic-12-07-2020-04

idsp: sciencepublic-12-07-2020-04

\section{Аннотация}

Предлагается методика расчёта свайных фундаментов исходя из критерия выбираемой (задаваемой) осадки (условия расчёта по второму предельному состоянию), для эквивалентно условного фундамента глубокого заложения.

Рассмотрена графическая интерпретация методики расчёта с определением площади эквивалентно условного фундамента глубокого заложения. Приведён численный пример решения кустового свайного фундамента в зависимости от деформационных свойств основания. Полученные решения оптимизируются по выравненной осадке. Предложена формула определения необходимого числа свай, обладающих одинаковой осадкой, что позволяет снизить неравномерность относительной осадки рядом расположенных фундаментов до минимальных допустимых значений.

Ключевые слова: свайный фундамент, расчёт по второму предельному состоянию, заданная осадка, число свай, программный расчёт на сайте: http://www.buildcalc.ru, выравнивание неравномерности осадки свайного фундамента.

\section{Введение}

Основополагающие принципы расчёта фундаментов по заданной осадке рассмотрены в предыдущих работах автора [1, 2, 3]. В данных работах осадку упругопластического основания для фундамента заданного размера предлагается определять через вычисляемый многофункциональный коэффициент нелинейности упругопластического деформированного основания $\left(\mathrm{K}_{\mathrm{i}}\right)$.

Тогда:

$$
S_{i}=S_{y(R)} \times K_{i}
$$

где, $\mathrm{S}_{\mathrm{y}(\mathrm{R})}$ - осадка основания, соответствующая давлению равному расчётному сопротивлению грунта $\mathrm{R}$ (условная граница применимости теории линейно деформируемой среды), определяемая по рекомендациям Свода правил [4]; $\mathrm{S}_{\mathrm{i}}$ - осадка упругопластического основания для фундамента заданного размера, при давлениях $\mathrm{P}_{\mathrm{i}}$ превышающих R.

\section{Основные допущения.}

Использование основы данного метода для свайных фундаментов базируются на следующих основных принятых допущениях:

1. Для осадки свайного куста примеряется эквивалентно условный фундамент глубокого заложения с глубиной залегания подошвы в уровне расположения острия свай.

2. Предельное давление на грунт основания для эквивалентно условного фундамента глубокого заложения вычисляется на основе решений Березанцева В.Г., Глушкевич С.С., Соколовского В.В., которые реализованы в современном Своде правил [4]. 
В соответствии с первым принятым допущением расчётная схема кустового эквивалентно условного свайного фундамента может быть представлена на рис. 1.

Тогда среднее давление $\left(\mathrm{P}_{\mathrm{i}}\right)$ под подошвой эквивалентно условного фундамента может быть определено из следующего выражения:

$$
P_{i}=\frac{N_{0}+N_{y}}{b_{y} \times \ell_{y}}=\frac{N_{0}}{b_{y} \times \ell_{y}}+d_{y} \times \gamma_{\mathrm{cp} .}
$$

где, N0 - нагрузка по обрезу свайного фундамента;

$N_{y}=d_{y} \times b_{y} \times \ell_{y} \times \gamma_{\text {cp. }}$ - осреднённый вес эквивалентно условного фундамента, включающий в себя вес свай, ростверка, и грунта в межсвайном пространстве; dy глубина эквивалентно условного фундамента; by, $\ell$ - ширина и длина эквивалентно условного фундамента (в первом приближении данные величины могут быть заданы исходя из условий минимальных конструктивных размеров ростверка); $\gamma с р$. осреднённое значение удельного веса эквивалентно условного фундамента.

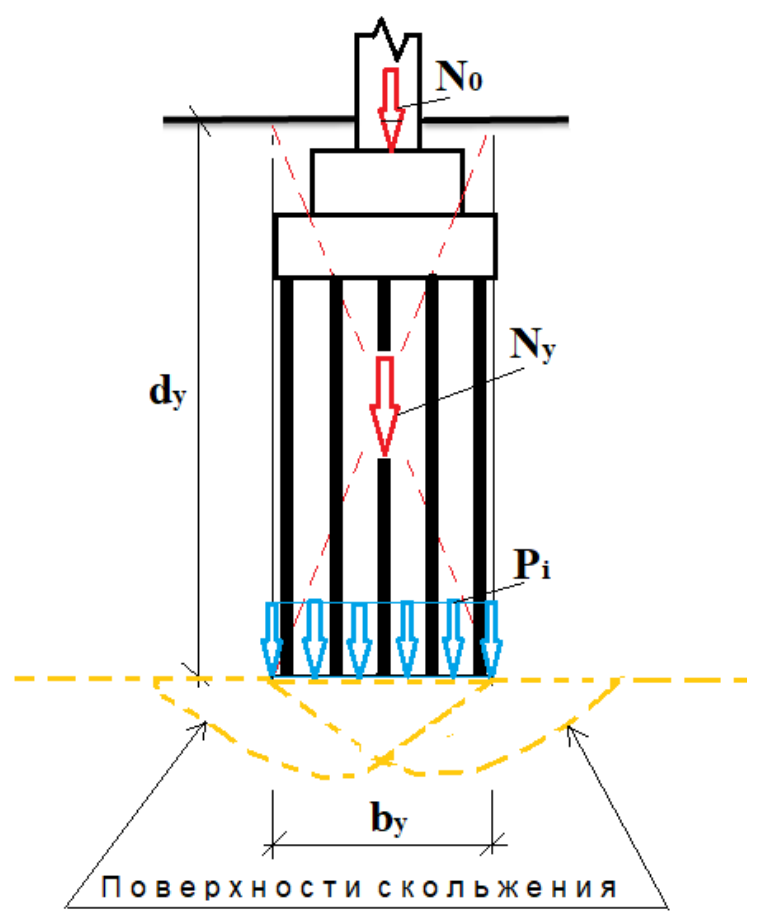

Рис. 1. Расчётная схема эквивалентно условного свайного фундамента, с формированием поверхностей скольжения по решению Березанщева В.Г. [5]

\section{Графическая интерпретация результатов расчёта.}

На основе второго принятого допущения, используя выражение (1), представляется возможность, задаваясь предварительно различной величиной $\left(b_{y}\right)$ (рядовое расположение свай под стену или условная ширина подошвы свайного куста), построить графики расчётной зависимости $\mathrm{S}_{\mathrm{i}}=\mathrm{S}_{\mathrm{i}}\left(\mathrm{P}_{\mathrm{i}}\right)$ (рис. 2).

Решения в соответствии с уравнением (2) может быть реализовано в виде расчётных графических зависимостей $\mathrm{P}_{\mathrm{i}}=\mathrm{P}_{\mathrm{i}}\left(\mathrm{b}_{\mathrm{yi}}\right)$, которые для различных расчётных сечений $(\mathrm{N}-\mathrm{N})$ свайного фундамента в зависимости от нагрузки, представлены кривыми 1-1, 2-2, 3-3 (рис. 3).

В соответствии с условиями поставленной задачи, задаёмся величиной осадки, при которой будем рассчитывать свайный фундамент. Графическая интерпретация такого решения представлена на рис. 2. Тогда, по заданной осадке $\left(\mathrm{S}_{\mathrm{A}}\right)$ (см. стрелочную идентификацию на рис. 2), находят значения давлений $\mathrm{P}_{1}, \mathrm{P}_{2}, \mathrm{P}_{3}$, соответствующие $\mathrm{b}_{\mathrm{y}}$, $\mathrm{b}_{\mathrm{y} 2}, \mathrm{~b}_{\mathrm{y} 3}$ - задаваемым величинам ширины подошвы эквивалентно условного фундамента. 


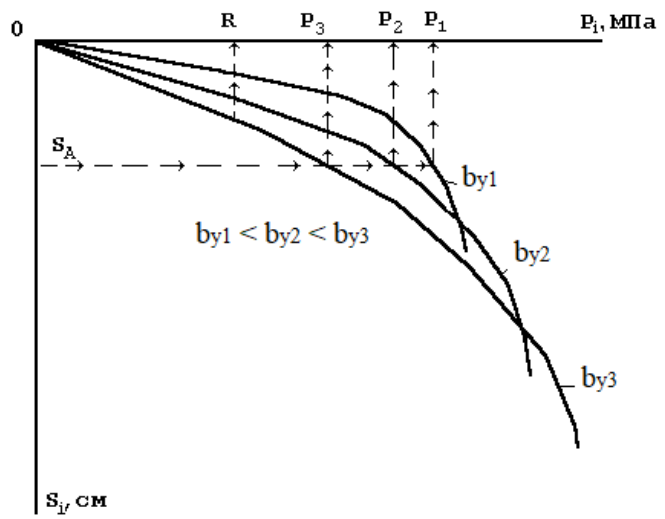

Рис. 2. Графики расчётной зависимости (1) осадки $\left(S_{i}\right)$ от прикладываемого давления $\left(P_{i}\right) \quad$ на основание; $b_{y 1}, b_{y 2}, b_{y 3}-$ задаваемая величина ширины подошвы эквивалентно условного фундамента

Найденные пары значений $\mathrm{P}_{1}$ и $\mathrm{b}_{\mathrm{y} 1} ; \mathrm{P}_{2}$ и $\mathrm{b}_{\mathrm{y} 2} ; \mathrm{P}_{3}$ и $\mathrm{b}_{\mathrm{y} 3}$ из решений на рис. 2 , наносят на график $\mathrm{P}_{\mathrm{i}}=\mathrm{P}_{\mathrm{i}}\left(\mathrm{b}_{\mathrm{yi}}\right)$ (рис. 3) в виде отдельных точек, соединяя которые получаем кривую А, соответствующую равной заданной осадки $\left(\mathrm{S}_{\mathrm{A}}\right)$.

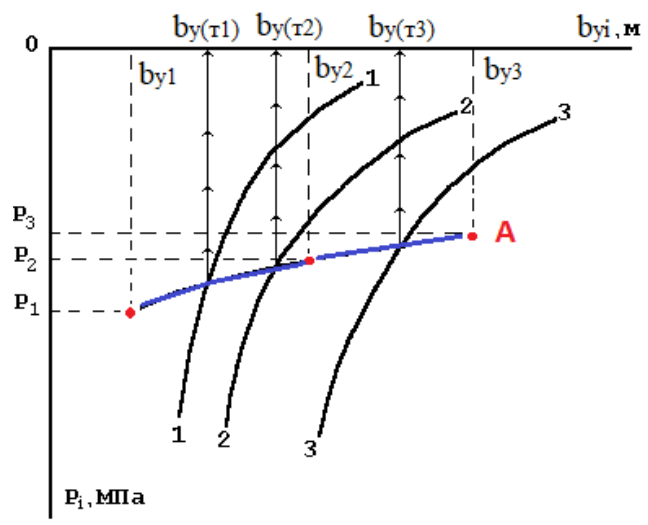

Рис. 3. Графики расчётной зависимости (2) $P_{i}=P_{i}\left(b_{y i}\right)$; 1-1, 2-2, 3-3 - кривые давлений для различныхх расчётных сечений ( $N$-N) свайного фундамента в зависимости от нагрузки; $A$ - кривая равной заданной осадки $S_{A} ; b_{y(m 1)}, b_{y(m 2),} b_{y(m 3),}$ - размеры требуемой ширины подошвы эквивалентно условного фундамента

Совместное решение или пересечение кривых давлений 1-1, 2-2, 3-3 для различных расчётных сечений свайного фундамента в зависимости от нагрузки и возможного изменения ширины подошвы эквивалентно условного фундамента (рис. 3) с кривой A - определит требуемые размеры подошвы эквивалентно условных свайных фундаментов $b_{y(\tau 1),} b_{y(\tau 2),} b_{y(\tau 3),}$ соответствующие равной заданной осадке $\left(\mathrm{S}_{\mathrm{A}}\right)$.

Следует подчеркнуть, что все, представленные на рис. 3, расчётные значения свайных фундаментов будут иметь различные размеры подошвы эквивалентно

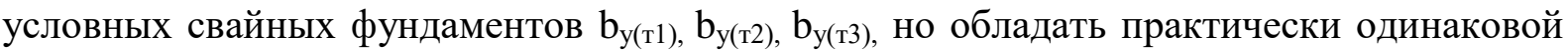
осадкой.

\section{Определение необходимого количества свай.}

Определив, таким образом, ширину подошвы требуемого эквивалентно

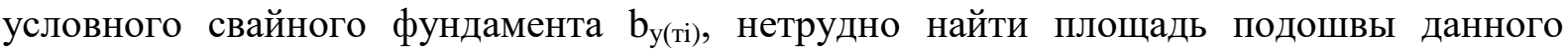
фундамента: $\mathrm{A}_{\mathrm{yc}}=b_{\mathrm{y}(\mathrm{T})} \times \ell_{\mathrm{y}}$.

Таким образом, на полученной в результате расчёта, площади $\left(\mathrm{A}_{\mathrm{yc}}\right)$ эквивалентно условного свайного фундамента должны быть размещены сваи. Учитывая, что площадь передачи давления от одной сваи может быть принята $(3 \mathrm{~d})^{2}$, получим необходимое (n) число свай:

$$
n=\frac{A_{y c}}{(3 d)^{2}}
$$

где, d - условный диаметр сваи. 
Определив по формуле (3) необходимое количество свай, получаем решение, которое будет соответствовать той заданной осадке (SA) при которой производился расчёт. Следовательно, поставленная задача практически решена.

Следует подчеркнуть, что проведя подобные расчёты для другого свайного фундамента, при другой степени нагружения, но при той же заданной осадке (SA), получаем другое количество свай, но обладающих одинаковой осадкой, что позволяет снизить неравномерность относительной осадки рядом расположенных фундаментов до минимальных допустимых значений.

\section{Численный пример по предлагаемой методике расчёта.}

Представленная интерпретация графического решения рассматриваемой методики (рис. 2, 3), может быть рассмотрена и в аналитической форме. Решения осуществляем по программе автора «BRNL», размещённой на сайте: http://www.buildcalc.ru/ [7].

Для примера выполним расчёт куста столбчатого эквивалентно условного свайного фундамента, при длине свай 12 м и вертикальной расчётной нагрузи в 4350 кН. Основные исходные данные, а также грунтовые условия, с модулем деформации основания в 20 МПа, представлены в нижерасположенной табличной форме. Следует подчеркнуть, что расчёт эквивалентно условного свайного фундамента, с учётом не линейной работы основания, (рис.4) производится по двум предельным состояниям, с определением (две последние строки в таб. «Рассчитанные данные по основанию») коэффициента надёжности и величины осадки, которая может, как задаваться, так и определяться по заданным размерам подошвы. Используя последнее условие, получим:

\section{BuildCalc}

расчёты в строительстве

BRNL - Расчёт фундамента с учётом нелинейной работы основания

Отчёт результатов расчёта:

Учётные данные

\begin{tabular}{|l|l|}
\hline Объект: & $\begin{array}{l}\text { Пример расчёта куста эквивалентно условного свайного фундамента с модулем } \\
\text { деформации основания в } 20 \text { МПа }\end{array}$ \\
\hline Тип здания: & Бескаркасное здание из кирпича без армирования \\
\hline
\end{tabular}

Данные по фундаменту

Основные данные фундамента

\begin{tabular}{|l|c|}
\hline Тип фундамента: & Столбчатый \\
\hline Тип стены: & Внутренняя \\
\hline Высота фундамента (размер фундамента от обреза до подошвы), м: & 12.00 \\
\hline $\begin{array}{l}\text { Глубина заложения фундамента (расстояние от планировочной отметки до подошвы } \\
\text { фундамента), м: }\end{array}$ & 12.00 \\
\hline Ширина подошвы фундамента, м: & 3.00 \\
\hline
\end{tabular}

Данные столбчатого фундамента

Соотношение сторон подошвы фундамента N = L / B: 1.00

Нагрузки по обрезу фундамента

\begin{tabular}{|c|c|}
\hline Вертикальная нагрузка N, кH: & $4,350.00$ \\
\hline Горизонтальная нагрузка, приложенная поперёк ширины подошвы фундамента Qв & 0.00 \\
\hline Изгибающий момент, приложенный поперёк ширины подошвы фундамента $\mathrm{M}_{\mathrm{B}}$, кН*м: & 0.00 \\
\hline Горизонтальная нагрузка, приложенная вдоль длины подошвы фундамента $\mathrm{Q}_{\mathrm{L}}$, кH: & 0.00 \\
\hline Изгибающий момент, приложенный & 0.00 \\
\hline
\end{tabular}


Данные по грунту

Введённые данные

\begin{tabular}{|c|c|c|c|c|c|c|c|c|c|c|c|c|}
\hline № & $\begin{array}{l}\mathrm{H}, \\
\mathrm{M}\end{array}$ & $\begin{array}{l}\text { Наиме- } \\
\text { нование }\end{array}$ & Тиі грунта & $\begin{array}{c}\gamma, \\
\kappa H / \mathbf{m}^{3}\end{array}$ & $\varphi,^{\circ}$ & $\begin{array}{c}\text { C, } \\
\mathbf{k} \Pi \mathbf{a}\end{array}$ & e & $\mathbf{W}$ & $\mathrm{I}_{\mathrm{L}}$ & $\mathbf{E}$ & $\mu$ & $\begin{array}{c}\text { Источник } \\
\text { данных }\end{array}$ \\
\hline 1 & 30 & Песок & $\begin{array}{c}\text { Пески пылеватые } \\
\text { насыщенные водой }\end{array}$ & 17 & 34 & 0 & 0.7 & - & - & 20000 & 0.3 & Эксперимент \\
\hline
\end{tabular}

Расчётные данные

\begin{tabular}{|c|c|c|c|c|c|c|c|c|c|c|}
\hline № & $\mathbf{H}, \mathbf{M}$ & $\gamma_{1}, \mathbf{K H} / \mathbf{m}^{3}$ & $\gamma_{2}, \mathbf{K H} / \mathbf{m}^{3}$ & $\varphi_{1},{ }^{\circ}$ & $\varphi_{2},{ }^{\circ}$ & $\mathbf{C}_{1}, \mathbf{K} \Pi \mathbf{a}$ & $\mathbf{C}_{2}, \mathbf{K \Pi a}$ & $\gamma_{\mathrm{c} 1}$ & $\gamma_{\mathrm{c} 2}$ & $\mathbf{K}$ \\
\hline 1 & 30.00 & 15.45 & 17.00 & 30.91 & 34.00 & 0.00 & 0.00 & 1.10 & 1.16 & 1.00 \\
\hline
\end{tabular}

Дополнительная информация

Грунтовые воды

Грунтовые воды отсутствуют

Информация о сооружении

\begin{tabular}{|l|l|}
\hline Сооружение обладает жёсткой конструктивной схемой \\
\hline Отношение длины сооружения или его отсека к высоте: & 2.00 \\
\hline
\end{tabular}

Справочная информация

\begin{tabular}{|c|c|}
\hline Удельный вес минеральных частиц грунта, кН/м³ : & 27.00 \\
\hline Удельный вес воды, кН/ ${ }^{3}$ : & 10.00 \\
\hline
\end{tabular}

Результаты расчёта

Рассчитанные данные по совместной работе грунта и фундамента

\begin{tabular}{|c|c|}
\hline $\begin{array}{l}\text { Средневзвешенное значение удельного веса грунта по I-му предельному состоянию выше } \\
\text { подошвы фундамента, кН/м²: }\end{array}$ & 15.45 \\
\hline $\begin{array}{l}\text { Средневзвешенное значение удельного веса грунта по II-му предельному состоянию выше } \\
\text { подошвы фундамента, кH/м²: }\end{array}$ & 17.00 \\
\hline Приведённая глубина заложения фундамента $\mathrm{d}_{1}$, м: & 12.00 \\
\hline
\end{tabular}

Рассчитанные данные по основанию

\begin{tabular}{|c|c|}
\hline Расчётное сопротивление грунта основания R, кПа: & $2,101.66$ \\
\hline Предельное давление (несущая способность) грунта основания $P_{\text {пр }}$, кПа: & $\underline{9,961.43}$ \\
\hline Предельная нагрузка на фундамент $\mathrm{N}_{\text {пр }}$, кH: & $89,652.86$ \\
\hline Минимальное давление под подошвой фундамента $\mathrm{P}_{\min }$, кПа: & 723.33 \\
\hline Среднее давление под подошвой фундамента $\mathrm{P}_{\text {ср., }}$ кПа: & 723.33 \\
\hline Максимальное давление под подошвой фундамента $\mathrm{P}_{\max }$, кПа: & 723.33 \\
\hline Осадка эквивалентно условного свайного фундамента S, см: & 8.74 \\
\hline Коэффициент надёжности эквивалентно условного свайного фундамента: & 12.39 \\
\hline
\end{tabular}

Рис. 4. Пример результатов расчёта куста эквивалентно условного свайного фундамента по двум предельным состояниям, с учётом не линейной работы основания с модулем деформации в 20 МПа

Следует подчеркнуть, что не линейная работа основания, за счёт развития зон пластических деформаций под подошвой эквивалентно условного фундамента глубокого заложения, обусловлена в основном величиной предельного давления грунта основания (несущая способность), которая составляет: Рпр.= 9961.43 кПа (рис. 4, вторая строка таб. «Рассчитанные данные по основанию»).

Необходимо отметить, что подобные программные решения могут быть многократно повторены при любых изменениях начальных условий, рассматриваемой задачи. Это позволяет провести анализ и оптимизацию получаемых решений. Пример интерпретации такого подхода представлен в графическом виде на рис. 5. 


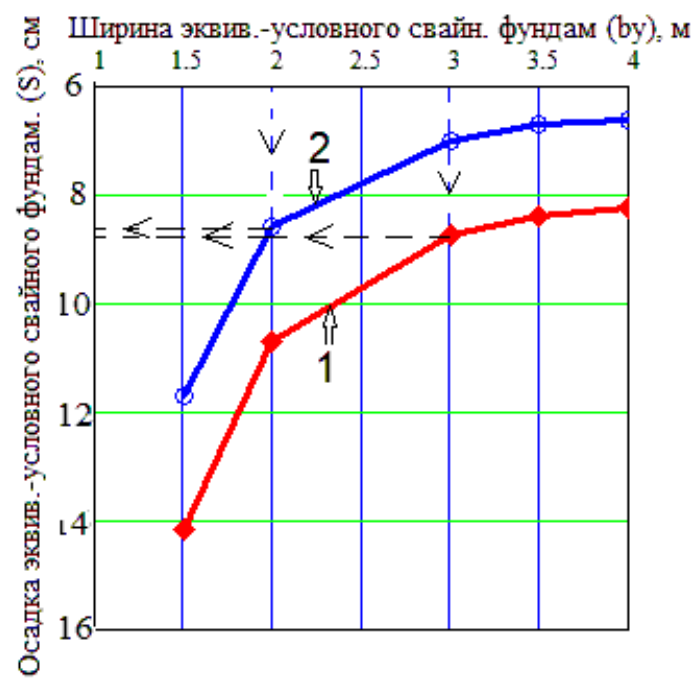

Рис. 5. Расчётная зависимость осадки (S) куста эквивалентно условного свайного фундамента от его ширины (by), по условиям рассматриваемого примера. 1 - основание с модулем деформации в 20 МПа; 2 - основание с модулем деформации в 25 МПа

Результаты решений программного расчёта (рис. 5) позволяют построить графические зависимости осадки $(\mathrm{S})$ условного свайного фундамента от его ширины $\left(\mathrm{b}_{\mathrm{y}}\right)$ или $(b)_{\mathrm{y}}=\left[(b)_{\mathrm{y}}\right](s)$. В данном примере построены две кривые 1 и 2 (рис. 5), отличающиеся деформационными свойствами оснований. При анализе полученных зависимостей, очевидно, что для кривой 1 при ширине подошвы эквивалентно условного свайного фундамента $\left(b_{y}\right) \geq 3$ м осадка данного эквивалентно условного свайного фундамента $(\mathrm{S})$ практически стабилизируется в размере $8,5 \mathrm{~cm}$, для кривой 2 (основание с модулем деформации в $25 \mathrm{MПа)} \mathrm{подобная} \mathrm{оптимальная} \mathrm{осадка} \mathrm{составляет}$ около $7 \mathrm{~cm}$.

Таким образом, данные величины осадок следует считать оптимальными для рассматриваемых грунтовых условий и действующих нагрузок.

Анализируя полученные зависимости (рис. 5) по условиям одинаковой (допустимой для данного вида сооружения) осадки, не трудно заметить:

- $\quad$ для основания с модулем деформации в 20 МПа (кривая 1 или для 1 фундамента), при осадке 8,74 см ширина подошвы эквивалентно условного свайного фундамента составит 3 м.

- для основания с модулем деформации в 25 МПа (кривая 2 или для 2 фундамента), при осадке 8,56 см ширина подошвы эквивалентно условного свайного фундамента составит 2 м.

Следовательно, и 1 и 2 свайные фундаменты будут давать практически одинаковую осадку (с минимальной неравномерностью относительной осадки), с соответствующей требуемой шириной эквивалентно условного фундамента $b_{y(\tau 1)}=3 \mathrm{M}$ и $\mathrm{b}_{\mathrm{y}(\mathrm{T} 2)}=2 \mathrm{M}$.

Определив, таким образом, ширину подошвы требуемых эквивалентно условных

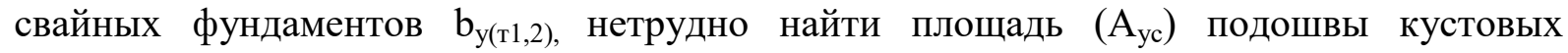
столбчатых эквивалентно условных фундаментов и, используя формулу (3), рассчитать необходимое (n) число свай:

$$
n_{1}=\frac{\mathrm{A}_{\mathrm{yc}}}{(3 d)^{2}}=\frac{9}{(3 \cdot 0,3)^{2}}=11 ; \quad n_{2}=\frac{4}{(3 \cdot 0,3)^{2}}=5 \text {. }
$$

Таким образом, по условиям рассматриваемого примера, два свайных фундамента, устраиваемые в основаниях с модулем деформации в 20 МПа и 25 МПа, для получения практически одинаковой осадки в размере около 8,6 см, должны иметь соответственно минимальное количество 11 и 5 забивных свай сечением 30х30 см. 
Следует подчеркнуть, что проектирование свайных фундаментов по величине задаваемой осадке (II предельное состояние) позволяет снизить неравномерность относительной осадки рядом расположенных фундаментов до минимальных допустимых значений (учёт неоднородности грунтовых оснований и различной степени нагружения), что создаёт наиболее благоприятные условия для работы надземных конструкций сооружения.

Для внецентренно нагруженных свайных фундаментов, представленную методику необходимо дополнить определением горизонтальной составляющей в уровне головы свай и выполнить расчётную проверку ж/б стволов свай на изгиб в соответствии с рекомендациями СП 24.13330.2011 [6].

\section{Выводы.}

1. Использование предлагаемой методики расчёта свайных фундаментов в отличие от традиционного способа [6], не предполагает определение несущей способности свай, проведение их испытаний и расчёта осадки, что обладает существенным экономическим эффектом.

2. Проектирование свайных фундаментов по величине задаваемой осадке (II предельное состояние) позволяет снизить неравномерность относительной осадки рядом расположенных фундаментов до минимальных допустимых значений, что создаёт наиболее благоприятные условия для работы надземных конструкций сооружения.

\section{$* * *$}

1. Алексеев С. И. Инженерный метод проектирования фундаментов по выровненным осадкам. Основания, фундаменты и механика грунтов № 5, 1998, М., Стройиздат.

2. Алексеев С. И. Проектирование ленточных фундаментов по заданной осадке с учётом двух предельных состояний http://www.buildcalc.ru/Articles/Open.aspx?id=2015022201 , 2015 г.

3. Алексеев С. И. Механика грунтов, основания и фундаменты. Избранные главы. Учебное пособие (для магистрантов и аспирантов строительных специальностей), Издательство АСВ. М. 2019 г.

4. Свод правил. СП 22.13330.2016. Основания зданий и сооружений. Актуализированная редакция СНиП 2.02.01-83*. Режим доступа: http://docs.cntd.ru/document/456054206

5. Березанцев В. Г. Расчёт оснований сооружений. (Пособие по проектиро-ванию). Л. 1970 г.

6. Свод правил. СП 24.13330.2011. Свайные фундаменты. Актуализированная редакция СНиП 2.02.03-85. http://docs.cntd.ru/document/1200084538

7. BRNL - Расчёт размеров и осадки существующего или нового фундамента с учётом возможной нелинейной работы основания. СВИДЕТЕЛЬСТВО о государственной регистрации программы для ЭВМ № 2015615210. Официальный бюллетень федеральной службы по интеллектуальной собственности (РОСПАТЕНТ) № 6 (104) 2015, 20.06.2015 г. 


\title{
РАЗДЕЛ ІІІ. ФИЗИКА
}

\author{
Сафаров Ш.Р. ${ }^{1}$, Ойматова Х.Х. ${ }^{1}$, Рафиев С.С. ${ }^{2}$, Сафаров М.М. ${ }^{3}$, Файзова М.А. ${ }^{1}$ \\ Расчет одного из основных термодинамических потенциалов (энергия \\ Гельмгольца) тернарных систем \\ ${ }^{1}$ Бохтарский государственный университет имени Носира Хусрава \\ (Таджикистан, Бохтар) \\ ${ }^{2}$ Институт энергетики Таджикистан \\ (Таджикистан, Кушониен) \\ ${ }^{3}$ Филиал МГУ имени М.В.Ломоносова в г.Душанбе \\ (Таджикистан, Душанбе)
}

doi:10.18411/sciencepublic-12-07-2020-05

idsp: sciencepublic-12-07-2020-05

\section{Аннотация}

В данной статье рассматриваются основные термодинамические потенциалы (энергия Гельмгольца) тернарных систем, кремниевой кислоты, многослойной углеродной нанотрубки и нанопорошка гидразина.

В данной работе для исследования был использован сканирующий колориметр интервала температуры от $290 \mathrm{~K}$ до 650К. Материалы тернарных систем были исследованы и при нагревании до температуры 620 К (таблица 1 , рисунок 1) и при охлаждении (таблица 2, рисунок 2). По графикам видно, что максимальное значение энергии Гельмгольца появляется при фазовом переходе (при нагревании) или за счет сильного изменения температуры (при охлаждении).

Как видно из таблицы, при охлаждении для всех опытах исследуемых объектов, процесс идет самопроизвольно в прямом направлении $(\Delta \mathbf{F}<\mathbf{0})$.

Ключевые слова: энергия Гельмгольц, тернарная система, температура, термодинамические характеристики, наночастиц, гидразин, кремниевая кислота, многослойная углеродная нанотрубка.

Введение и теория. Состояние термодинамического равновесия чрезвычайно устойчиво, так как при постоянстве $\mathrm{V}$, Т система выйти из равновесного состояния не может, так как выход равен возрастанию энергии Гельмгольца. Чтобы система вышла из состояния равновесия необходимо изменить какие-либо внешние факторы $(\mathrm{V}, \mathrm{T}$, концентрация и так далее). В нашем случае мы изменили один из внешних факторов (T) т. е. наша система исследована зависимости от изменения температуры [1].

В статье рассматривается изменение одного из основных термодина-мических потенциалов (энергия Гельмгольца) тернарных систем.

Объектом исследования являются система, которая состоит из трёх компонентов, нанопорошка гидразина, многослойной углеродной нанотрубки и кремниевой кислоты - такая система называется тернарная.

Экспериментальная часть. Изменение энергии Гельмгольца для исследуемых тернарных смесей экспериментально было изучено сканирующим калориметром.

Результаты и их обсуждение. Для решения поставленной задачи на первом этапе были рассчитаны энтропия, энтальпия и внутренняя энергия. Эти параметры мы будем использовать для дальнейшего расчёта. С помощью уравнения (5) нами рассчитан термодинамический потенциал, исследуемая объекта для три концентрации. Результаты расчета одной из концентрации (концентрация №1) приведены в таблице 1.

Как видно из таблицы 1, во всех опытах при нагревании исследование объекта система протекает в обратном направлении т. е. $\Delta \mathbf{F}>\mathbf{0}$. Только первые значения в 
первом и во втором опыте энергия Гельмгольца равна нулю $(\Delta \mathbf{F}=\mathbf{0})$ т.е. система находится в состоянии равновесия.

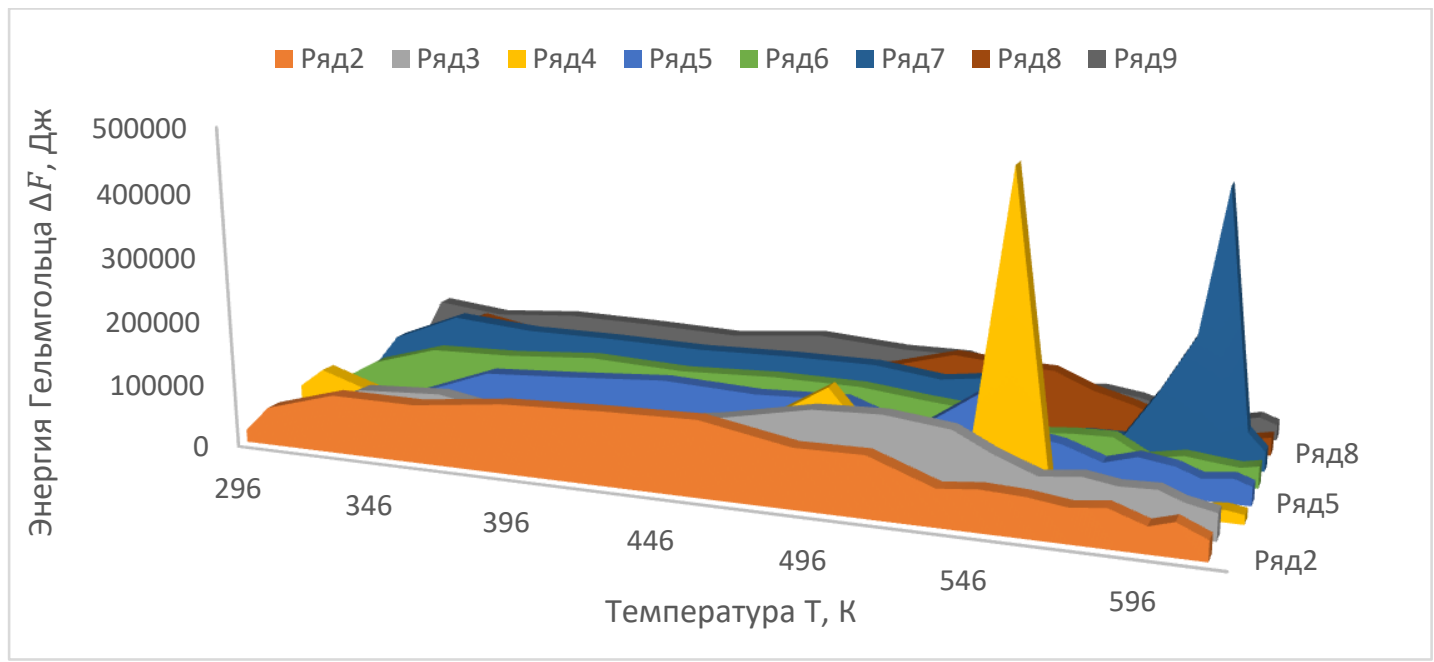

Рисунок 1. Изменение энергии Гельмгольиа в тернарных системах при нагревании. Ряд1,2,3 это опьты первой концентрации- $\left(2 \mathrm{O}_{2}\left(\mathrm{H}_{2} \mathrm{SiO}_{4}\right)+52\left(\mathrm{~N}_{2} \mathrm{H}_{4}\right)+12(\right.$ УHT)); Ряд4,5,6 это опыты второй концентрации $\left(252\left(\mathrm{H}_{2} \mathrm{SiO}_{4}\right)+102\left(\mathrm{~N}_{2} \mathrm{H}_{4}\right)+1,2\right.$ г (УHT)); Ряд7,8,9 это опьтын второй концентрации - $\left(302\left(\mathrm{H}_{2} \mathrm{SiO}_{4}\right)+152\right.$ $\left.\left(\mathrm{N}_{2} \mathrm{H}_{4}\right)+1,52(\mathrm{YHT})\right)$.

Из графика (рисунок 1) видно, что при нагревании исследуемой системы в первых опытах во всех образцах получается самое большие значение энергии Гельмгольца. Это связанно с фазовым превращением. Фазовые переходы появляются за счёт влияния нанопорашка гидразина. На других опытах в интервале температуры от $320^{\circ} \mathrm{C}$ до $430^{\circ} \mathrm{C}$ значение энергии Гельмгольца получается больше чем в других интервалах. Это потому, что в этом значение изменение температуры больше.

Вывод: Самопроизвольно могут протекать в прямом направление только те процессы, которые приводят к понижению свободной энергии системы (в нашем случай при охлаждение); система приходит в состояние равновесия, когда свободная энергия достигает минимального значения (перед нагревание). Процессы, которые сопровождаются увеличением термодинамических потенциалов, протекают лишь при совершении работы извне над системой.

$$
* * *
$$

1. http://zadachi-po-khimii.ru/obshaya-himiya/energiya-gibbsa-energiya-gelmgolca-napravlenieprocessa.html. 


\title{
РАЗДЕЛ IV. МАШИНОСТРОЕНИЕ
}

\author{
Новиков Н.И., Новиков В.Н. \\ К вопросу устойчивости функционирования групповых производственных \\ систем \\ Филиал ФГБОУ ВО «Уфимского государственного авиащионного технического \\ университета» \\ (Россия, Кумертау)
}

doi:10.18411/sciencepublic-12-07-2020-06

idsp: sciencepublic-12-07-2020-06

Известно [1], что специализация, организация групповых производственных систем способствует своевременному и эффективному внедрению в производство новейших достижений науки и техники, наиболее рациональному использованию материальных, трудовых и финансовых ресурсов.

Опыт внедрения групповых производственных систем показал, что экономические показатели от внедрения групповой технологии не всегда обеспечиваются в полном объеме. При реализации расписания работы групповой производственной системы действуют различные возмущения. Это приводит к тому, что сформированные группы деталей/операций и закрепление их за рабочими местами нарушается. Таким образом, расписание работы групповой производственной системы нарушается, срываются заданные сроки изготовления деталей.

Корректировка исходного расписания работы групповой производственной системы путем изменения организационно-технологических решений осуществляется в момент появления узкого места, решения технологических и организационных задач принимаются на основе опыта, интуиции и сложившихся традиций, моделирование работы производственной системы для проверки принятых решений не выполняется. Это снижает устойчивость функционирования групповой производственной системы, снижается вероятность выполнения заказа в срок.

В существующих системах подготовки и управления групповыми производственными системами процессы принятия решений осуществляются не оперативно, на основании жестких алгоритмов.

На практике в понятие устойчивости вкладывается довольно широкий смысл: от понятия нормального функционирования системы в целом в условиях всевозможных возмущений до понятия малости отклонений какого-либо отдельного параметра. Это обусловлено прежде всего сложностью производственных систем, необходимостью учитывать влияние на их функционирование большого числа факторов.

В работе под устойчивостью функционирования групповой производственной системы подразумевается обеспечение минимального отклонения длительности производственного цикла изготовления деталей от заданного по отношению к возмущению или неопределённости некоторых параметров системы или её математической модели.

Устойчивость групповых производственных систем выступает как неотъемлемое свойство групповой производственной системы без выполнения которого не могут быть реализованы другие свойства системы.

Поэтому для групповых производственных систем проблема обеспечения устойчивости является актуальной.

Для обеспечения устойчивости функционирования групповой производственной системы требуется тщательная проработка вопросов устойчивости на стадиях формирования организационно-технологических решений. 
В работе определяется показатель устойчивости функционирования групповой производственной системы относительно расчетного (заданного) графика функционирования групповой производственной системы [3]:

$$
Y=T^{3}{ }_{\text {u.coв }} / T^{n}{ }_{\text {u.coв. }}
$$

где $T^{3}$ и.сов - заданная совокупная длительность производственного цикла изготовления партий деталей;

$T^{n}{ }_{4 . с о в}$ - прогнозная совокупная длительность производственного цикла изготовления партий деталей.

Если показатель устойчивости меньше заданного, то осуществляется поиск решений по повышению устойчивости функционирования групповой производственной системы.

В работе реализован подход к повышению устойчивости функционирования групповых производственных систем путем введения информационной избыточности в управляющей системе и в управляемом объекте.

В работе используется изменение следующих параметров для повышения устойчивости функционирования групповой производственной системы:

— структуры технологических процессов (операций) изготовления деталей;

— перегруппирование деталей/операций;

- специализация рабочих мест;

— очередности запуска партий деталей в обработку;

- изменение вида движения партий деталей;

- дробление партий запуска деталей.

В работе при формировании организационно- технологических решений формируются обобщенные группы деталей, обобщенные групповые технологические процессы изготовления детали, которые характеризуются определенной степенью избыточности.

Знания об условиях изменения группы деталей, структуры технологических процессов (операций), параметров производственной системы формируются в виде базы знаний системы поддержки и принятия решений.

При создании моделей обобщенных групп деталей, обобщенных технологических процессов и их взаимосвязей в работе использовались формы представления знаний в виде фреймов и правил продукций.

Это позволило адекватно и удобно представить знания технологов, плановиков, диспетчеров.

В работе создана система представления вариантов групп деталей, структур технологических процессов изготовления деталей, организационно-технологических решений, разработан интерфейс системы поддержки и принятия решений [3].

На этапе планирования производства с помощью системы поддержки и принятия решений на базе информации с ERP системы выполняется формирование параметров исходной стратегии изготовления групп деталей.

Параметрами исходной стратегии изготовления группы деталей в работе являются размер партии запуска детали, очередность запуска партий деталей в обработку, вид движения партий деталей, срок запуска партий деталей в обработку.

Система поддержки и принятия решений позволяет формировать стратегию обработки партий деталей, моделировать принятые решения, анализировать результаты моделирования и формировать организационно-технологические решения по повышению устойчивости функционирования групповой производственной системы.

Принимаемая на начальной стадии стратегия изготовления деталей носит предварительный характер и подлежит корректировке по результатам моделирования и диагностирования групповой производственной системы. 
Далее выполняется моделирование работы групповой производственной системы по исходной стратегии изготовления партий деталей.

Диагностирование производственной системы осуществляется на основании ситуативных признаков, получаемых при имитации функционирования групповой производственной системы.

При диагностировании различают исходные ситуативные признаки и дополнительные, которые получаются на последующих этапах моделирования и диагностирования при поиске решений по локализации отклонений.

Предлагаемая в работе система диагностирования ориентирована на процесс выявления отклонений от нормального хода производственного процесса и идентификацию состояний производственной системы.

В случае выявления отклонений производственного цикла изготовления деталей от заданного, отклонения ранжируются по величине отклонения и в первую очередь принимаются решения по локализации максимального отклонения длительности производственного цикла изготовления детали.

Поиск мероприятий по локализации отклонений прогнозируемого срока окончания выпуска партий деталей от заданного осуществляется с помощью экспертно-диагностической системы и имитационной модели.

В результате реконфигурирования производственной системы на базе обобщенной группы деталей и технологического процесса изготовления детали формируется оперативная группа деталей и технологический процесс изготовления партии деталей исходя из состояния ресурсов производственной системы.

Формирование организационно-технологических решений осуществляется с помощью разработанной системы поддержки принятия решений [4].

При выборе из заданного множества необходимой организационнотехнологических решений, структуры технологического процесса (операции) используется созданная база знаний [2].

Результаты выполненной работы показали, что повышение устойчивости функционирования групповых производственных систем возможно и целесообразно за счет использования информационной избыточности в управляющей системе и в управляемом объекте.

Применение в работе имитационной модели и экспертно-диагностической системы позволило повысить устойчивость функционирования групповых производственных систем за счет оперативной реконфигурации групп деталей, структуры технологического процесса изготовления детали.

Время поиска приемлемых организационно-технологических решений для локализации отклонений прогнозного цикла изготовления деталей от заданного уменьшается до 3-5 мин.

\section{***}

1. Митрофанов С.П. Групповая технология машиностроительного производства. В 2-х т. Т.1.Организация группового производства. 3-е изд., перераб. и доп.. - Л: Машиностроение, Ленингр. Отд-ние, 1983. - 407 с.

2. Новиков Н.И. К вопросу создания моделей автоматизированной системы подготовки и управления групповыми производственными участками // Вестник Оренбургского государственного университета. - 2015. -№ 4 (179). - С. 177-182.

3. Новиков Н.И., Новиков В.Н. Представление вариантов технологических процессов изготовления деталей в экспертно-диагностической системе автоматизированной системы организационнотехнологического проектирования. «Интеграция образования, науки и производства в условиях многоуровневого профессионального образования». Материалы IV Всероссийской научнопрактической конференции с международным участием/ Уфимск. гос. авиац. техн. ун-т.-Уфа: РИК УГАТУ, 2016.- С.198-205.

4. Новиков Н.И. Система поддержки решений при организации группового производства // Объектные системы - 2013: материалы VII Международной научно-практической конференции (Ростов на Дону, 10-12 мая 2013 г.) / Под общ. ред. П.П.Олейника.-Ростов-на Дону: ШИ (ф) ЮРГТУ(НП), 2013.-c.104-110. 


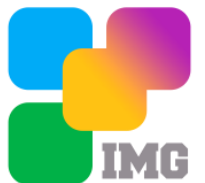

Научное издание

Научный диалог:

Вопросы точных и технических наук

Сборник научных трудов по материалам

XXIX международной научно-практической конференции

12 июля 2020 г.

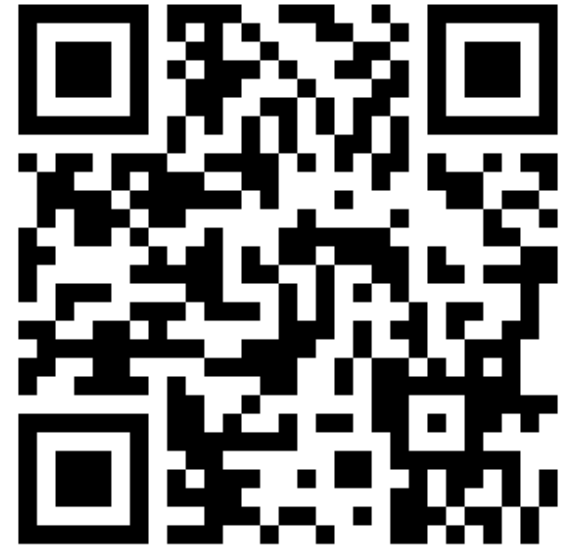

SPLN 001-000001-0668-TT

Подписано в печать 13.07.2020. Тираж 400 экз.

Формат.60х841/16. Объем уч.-изд. л.2,07

Бумага офсетная. Печать оперативная.

Отпечатано в типографии НИЦ «Л-Журнал»

Главный редактор: Иванов Владислав Вячеславович 